\title{
Mitos, cuentos de espantos y leyendas: tradición oral en el municipio del Socorro, Colombia
}

\author{
Jaqueline Estévez Lizarazo \\ Doctora de la Universidad Complutense de Madrid, Madrid, España \\ Profesora Asociada de la Universidad Pontificia \\ Bolivariana, Bucaramanga, Santander, Colombia \\ jaqueline.estevez@upb.edu.co \\ Oscar Eduardo Rueda Pimiento \\ Magister de la Universidad Industrial de Santander, Colombia \\ Profesor Asociado en la Universidad Pontificia \\ Bolivariana, Bucaramanga, Santander, Colombia \\ oscar.rueda@upb.edu.co \\ Giovanni Bohórquez-Pereira \\ Candidato a doctor en la Universidad de Zulia en Maracaibo, Venezuela \\ Profesor Asociado de la Universidad Pontificia \\ Bolivariana, Bucaramanga, Santander, Colombia \\ giovanni.bohorquez@upb.edu.co
}

Resumen La activación del patrimonio es el punto de partida para varios objetivos. Uno de ellos es la salvaguarda, que comienza con inventariar y catalogar el patrimonio cultural de un país, una región o comunidad. Este procedimiento enfrenta desafios particulares cuando se trata de manifestaciones de la tradición oral y este es el caso de patrimonios orales como los que en Colombia reciben el nombre de "cuentos de espantos", historias tenebrosas y espeluznantes relacionadas con personajes y espacios sobrenaturales. Adicional a esto, la ausencia de normatividad, ajustada a las necesidades de la tradición oral o de antecedentes en investigación sobre el tema en el país, suponen dos grandes retos para los de puesta en valor de estos patrimonios. Este documento tiene el objetivo de discutir los desafios mencionados y presentar alternativas para superarlos, algo que en el contexto estudiado puede ser posible gracias a la articulación de la tradición oral con el turismo cultural.

Palabras claves: Tradición oral. Colombia. Patrimonio sobrenatural. Turismo cultural. Puesta en valor del patrimonio. 


\section{Cuentos de espantos, historias y narraciones sobrenaturales en Colombia}

La tradición oral asociada a personajes, eventos y territorios sobrenaturales en Colombia representa múltiples retos para su puesta en valor, derivados, en su mayoría, de las formas establecidas de gestión del patrimonio cultural en el país. Dos aspectos resumen los principales tropiezos que esas manifestaciones culturales enfrentan hoy de cara a los procesos de salvaguardia, inventariado y catalogación. Por un lado, las disposiciones y medidas pensadas para la protección del patrimonio cultural responden principalmente a modalidades de intervención y salvaguardia de carácter conservacionista y son ajenas a las particularidades de nuestra tradición oral (Henríquez, 2011); por otra parte, en la normatividad nacional, es evidente la persistencia de una concepción del patrimonio cultural a menudo restringida al terreno de "lo culto" (Pastor, 2003), la "cultura oficial" (Fernández, 2006) y con énfasis excesivo en lo monumental, lo histórico y lo artístico.

Categorías como patrimonios vivos y patrimonios culturales intangibles reconocen el carácter distintivo del patrimonio cultural inmaterial (PIC) y de las modalidades requeridas para su intervención (Guanche, 2014), y su adopción exige ajustar el marco normativo preexistente en la legislación nacional, ${ }^{1}$ así como un cambio en los procesos de inventariado y catalogación, promoción, protección y conservación del patrimonio. Con todo, la articulación de esas iniciativas a las normatividades preexistentes en los diferentes países no siempre resulta fácil. Así, aunque el Decreto n. 2.491, de 2009, represente para el país (Colombia) un avance importante en el tema, persiste en la legislación cultural de la nación una caracterización del patrimonio cultural de dificil asociación con el PIC (Rengifo, 2008).

Los paradigmas que gobiernan la relación que las sociedades de hoy mantienen con sus patrimonios son ejemplificados por el historiador Alejandro Araujo (2008) gracias a la asociación de esos paradigmas con las conductas de los personajes en el libro Historias de Cronopios y Famas. Para Araujo, nuestras relaciones con el pasado son asimilables a las de los personajes de la obra del escritor argentino Julio Cortázar. La primera se manifiesta cuando "el pasado está por todos lados" (Araujo, 2008, p. 95) y convive en armonía con el presente (es el caso en la sociedad compuesta por Cronopios). La segunda, cuando se pretende protegerle encapsulándolo y creando espacios e instituciones que lo conservan en su interior, lo catalogan y etiquetan como tal, usando criterios que se fundamentan en el distanciamiento y en la separación entre presente y pasado (propia de sociedades como las Famas).

La antropóloga Marta Farré (2014) considera, sin embargo, que los comportamientos descritos por Araujo no agotan las posibilidades existentes en cuanto a la relación de las sociedades humanas con el pasado. Para la antropóloga existen otras alternativas, resultado de la permanente hibridación entre ambas realidades. Este parece ser el caso de iniciativas reunidas por la autora bajo el nombre del coleccionismo de olvidos, a las

1 Legislación y normas generales para la gestión, protección y salvaguardia del patrimonio cultural en

Colombia. Ley n. 1.185 y su reglamentación, de 2010. 
cuales caracteriza como una "territorio fronterizo, de margen y de confluencias" (Farré, 2014, p. 5.552), donde la dimensión más individual y privada del coleccionismo y la más colectiva y pública del patrimonio se sitúan juntas, conformando verdaderos escenario de diálogo y de relación para las dicotomías comúnmente aceptadas y presentes en las lógicas hegemónicas que orientan la patrimonialización.

La tradición oral comparte las características propias del coleccionismo de olvidos. Con una particularidad adicional, la tradición oral es resultado de la acción conjunta de los mecanismos de la memoria, el olvido (accidental o no) y la imaginación, a partir de la cual se actualiza continuamente (Álvarez, 2012). Incluso la supervivencia de esta manifestación cultural depende del reconocimiento a tal particularidad, dado a que esta no ofrece nunca un estado permanente, sino uno transitorio, algo que contradice los intentos de negar que, como todos nuestros patrimonios culturales, la tradición oral ha pasado por diferentes trasformaciones y seguramente lo seguirá haciendo (Fernández, 2006). Así también contradice su condición como creación colectiva, en la cual "cada individuo interviene añadiendo, acentuando o suprimiendo aspectos, de manera que cada trasmisión supone una modificación" (Cortázar, 2004, p. 6).

Los retos que se enfrentan hoy en Colombia la gestión de patrimonios como cuentos de espanto, mitos y leyendas surgen a menudo de esa situación. Al igual que de la falta de alternativas innovadoras para su promoción, salvaguarda y puesta en valor.

La tradición oral ofrece una condición mutable que contrasta abiertamente con el paradigma tradicional que gobierna la gestión del patrimonio cultural, el cual supone su ajuste a una condición fosilizada, desconociendo su condición como patrimonio vivo, dinámico y que sobrevive gracias a que permanentemente es celebrado, vivido o rememorado. Esa circunstancia demandaría ajustar su puesta en valor a un proceso inverso al paradigma tradicional, el cual impone romper el vínculo que conecta los patrimonios con el presente y con sus portadores y aislarle de los contextos cotidianos para su preservación.

La materialización o fijación en soportes materiales de las actividades y expresiones vivas (por medio de registros documentales, sonoros o audiovisuales) o su museificación corresponden, así, a las modalidades más recurrentes de preservación de nuestros PIC.

A pesar de ese hecho, existen motivos para cuestionar la creencia según la cual "para proteger las culturas inmateriales, denominadas también 'culturas vivas', 2 hay que monumentalizarlas; hay que convertir lo inmaterial en material, lo 'vivo' en objeto, y hacerlo sujeto de conservación" (Romero, 2005, p. 48). Como sucede con casi todos los demás aspectos de una cultura, mantener la vitalidad de nuestros patrimonios orales hace que todo intento para evitar que varíen con el tiempo y que permanezcan inmóviles lleve a la obtención de un patrimonio irreal y artificial (Maderos, 2005, p. 82). Aspecto clave que justifica la necesidad de encontrar alternativas a la "idea de custodia, mantenimiento y conservación perenne de objetos o actividades que deben transmitirse intactos a las

2 El texto conserva la puntuación como se le emplea en la fuente original. 
nuevas generaciones" (Carrera, 2017, p. 7), como rectora de los procesos actuales de gestión de nuestro PIC.

La idea del patrimonio cultural como un conjunto de bienes que debe protegerse aislándole de sus comunidades y preservarle sin cambios "para su traspaso íntegro a las futuras generaciones" (Fernández, 2006, p. 4) resulta inadecuada en el caso particular de la tradición oral. Los siguientes apartados presentan argumentos para defender esta última afirmación y puntualizan algunos de los retos que se enfrentan hoy de cara a la salvaguarda de expresiones de la tradición oral como mitos, cuentos de espantos y leyendas, al tiempo que ofrecen alternativas la salvaguarda de esos patrimonios orales en contextos donde su articulación al turismo cultural es recomendable.

El material que se somete a análisis es resultado de un proyecto de investigación formulado con el objetivo de diseñar estrategias de activación, con propósitos turísticos, del patrimonio oral asociado a cuentos de espantos y aparecidos, mitos, leyendas y otras manifestaciones de la tradición oral en el municipio del Socorro, que en 2014 fue incluido en la Red Turística de Pueblos Patrimonio por el Ministerio de Comercio, Industria y Turismo.

\section{Metodología}

La investigación realizada corresponde a un estudio cualitativo de corte etnográfico, que emplea dos fuentes de información: la normatividad cultural nacional e internacional y las fuentes orales. Forma parte de un proyecto de investigación orientado a la documentación, recuperación y difusión de esas expresiones de la tradición oral: mitos, leyendas, cuentos de espantos y eventos sobrenaturales que recurrentemente son identificados como patrimonios orales del municipio del Socorro, en Santander (Colombia).

Para las fuentes escritas se implementó el método de consulta documental como estrategia metodológica (Suárez, 2011) centrada en el rastreo y caracterización de la normatividad cultural nacional e internacional. Los resultados de esa fase de investigación se registraron en una matriz para la organización, el análisis y la interpretación de la información, residiendo su importancia en el aporte de las pautas y de los lineamientos básicos que posteriormente pudieran profundizarse mediante la investigación de campo.

Para las fuentes orales se empleó el método de historia oral (Barela; Miguez; García, 2004), con el objetivo de reunir relatos de vida paralelos entre un grupo de informantes seleccionados bajo el principio de "bola de nieve" (Guber, 2003), lo cual hizo posible la recolección en campo de la tradición oral y una validación del corpus empleado en el actual trabajo, como resultado del proceso mismo de negociación de instrumentos de registro, entrevistas, transcripciones, etc. 


\section{Ni Cronopios, ni Famas. Retos de la tradición oral de cara a la normatividad cultural en Colombia}

La situación de los estudios en temas asociados a mitos, cuentos de espanto y leyendas en Colombia es ilustrativa de lo señalado para la tradición oral en general. Por lo general, las principales fuentes bibliográficas del tema consisten en recopilaciones de esos patrimonios, lo cual no carece de importancia. Sin embargo, faltan estudios que complementen esos esfuerzos, algo que resulta injustificable considerando las posibilidades que la tradición oral ofrece como material para los estudios sociales. Ahora, las ideas que sostienen una distinción disciplinar entre memoria e historia son fuertemente discutidas. Es decir, las fronteras entre memoria e historia fueron construidas, en principio, a partir de consideraciones metodológicas que se desdibujan hoy a medida que se generaliza el reconocimiento de las condiciones de validez y confiabilidad que legitiman a la memoria, y se disuelve la discutible distinción de esos relatos del pasado con otras formas de registro del mismo.

Así, sucede hoy que las fronteras entre historia y memoria se disuelven ante la demanda cada vez más acentuada de relectura y cuestionamiento de la historia oficial. Es decir, si bien el pensamiento historiográfico del siglo XIX y su comprensión positivista del trabajo del historiador consagraron la investigación con fuentes escritas y documentos impresos, el testimonio oral y la memoria se perfilan como los recursos que han de aportar a la historiografia del siglo XXI nuevos enfoques y preguntas alternativas que le hacen diferente de la historiografía tradicional (Ferrando, 2006). A esto se debe que se asocien hoy al pasado los prejuicios que condicionaron a la memoria a servir de fuente marginal en la Historiografía y sólo ser consultada por disciplinas como la Antropología y la Literatura. Al respecto, no se debe olvidar la participación privilegiada que tienen los testimonios orales y la memoria en nuestras tradiciones históricas, como sucede con los Cronistas de Indias y en los trabajos de historiadores clásicos como Heródoto, Plutarco y Suetonio. Así, el tránsito entre las dos formas de registro (material e inmaterial) es menos excepcional de lo que se suele creer y tan cotidiano como es en el caso de la imagen (gracias a la fotografia y al video) y de la palabra (cuando esta se graba por medios mecánicos).

Las fuentes orales fueron, sin lugar a dudas, la primera y la más antigua forma de hacer historia (Ferrando, 2006).

Lamentablemente, la tradición oral asociada a mitos, leyendas y cuentos de espantos continúa siendo una fuente poco frecuentada en la investigación histórica, resultado de circunstancias particulares que limitan el interés de los investigadores. Por ejemplo, el interés por esos temas suele estar restringido a sólo algunas de sus manifestaciones. Así, para el antropólogo Raúl Romero (2005), resulta evidente la dificultad que supone para la salvaguarda del patrimonio inmaterial urbano hechos como el que la misma Unesco, al introducir el concepto, se refiere más a las expresiones tradicionales de las zonas rurales, que considera están en peligro de desaparición, y deje de lado las llamadas culturas populares 
de carácter urbano y moderno, sustentada en una separación, acaso injustificada, entre lo popular, lo rural y lo moderno.

Como Raúl Romero, Ocarina Castillo (antropóloga e investigadora del Centro de Estudios del Desarrollo de la Universidad Central de Venezuela) considera necesario superar el discurso tradicional sobre la identidad y su relación con la cultura nacional, donde se impuso un discurso de multiculturalidad selectiva, dentro del cual "sólo tomamos en cuenta lo afrodescendiente, lo indígena y alguna que otra minoría cultural, pero obviamos los procesos enormes de migraciones y de hibridación que ocurrieron en el siglo XX" (Ocarina Castillo apud Roche, 2013).

Ahora, es posible que a esto se sume otra circunstancia. A menudo considerados como simples cuentos "asusta niños", puede parecer que esas narraciones sean un material inadecuado para su estudio. Por supuesto, se trata de una mera apariencia. Como sucede con otras manifestaciones de nuestra tradición oral, esas historias no sólo se caracterizan por hablar de la gente, de sus valores y de su historia, sirven también para satisfacer sus necesidades, ya sean éstas de tipo emocional, didáctico, estético o recreativo (Herrera, 2000). Por lo cual, entretener es el objetivo más evidente, y no el único que se persigue al contar estas historias.

El segundo reto obedece a las dificultades que ofrece la tradición oral de cara a su inventariado y catalogación. El concepto de tradición oral reúne todo "el conjunto de representaciones colectivas elaboradas por una cultura a través del tiempo y trasmitidas, de generación en generación, por medio del lenguaje oral" (Galindo; García; Valencia, 2003 , p. 19). La activación de esos patrimonios exige, en principio, la conformación de un listado de bienes de interés cultural identificados en un país, región o comunidad. Algo que no resulta fácil en casos como los que discute el actual trabajo, eso debido a que las clasificaciones propuestas por la normatividad cultural de Colombia son insuficientes y suponen desconocer el hecho de que al PIC no le conforman unidades autónomas, fáciles de aislar de las relaciones que les vinculan a otras manifestaciones del patrimonio y que les resultan esenciales para garantizar su supervivencia.

La Ley n. 1.185, de 2008, sería en Colombia la primera exclusivamente dedicada en el país al PIC, a la definición de sus particularidades, manifestaciones por las que está constituido, aspectos que le legitiman y formas como esos patrimonios son trasmitidos y recreados (art. 8). Al igual que las orientaciones internacionales, considera que la identificación de esas manifestaciones y los planes para su salvaguardia se deben hacer con la participación activa de las comunidades. El Decreto n. 2.941, de 2009, y la Resolución 0330, de 2010, por medio de los que se puntualizan algunos aspectos técnicos y administrativos para la gestión del PIC de la nación, suponen una ampliación a la Ley. Abogan en conjunto por una gestión del patrimonio mucho más participativa, un compromiso dificil de concretar si no se proveen primero herramientas que en el plano económico y social supongan un verdadero aporte a las condiciones requeridas por las comunidades para la autogestión y autodeterminación de sus patrimonios. 
La Unesco (Organización de las Naciones Unidas para la Educación, la Ciencia y la Cultura) invita hoy a reconocer la importancia y particularidad de esos patrimonios, tras promover en 2003 su declaratoria como "patrimonios vivos" y "patrimonio cultural intangible". A pesar de ese hecho, las propuestas de catalogación del PIC en Colombia se encuentran aún lejos de reunir las condiciones para servir de marco en la conformación de lista de PIC de la nación y su inventariado. Asignando, por ejemplo, a patrimonios orales como cuentos de espanto, mitos y leyendas, un lugar generalmente enunciativo dentro del campo de las artes populares, junto a la recreación de tradiciones musicales, dancísticas, literarias, audiovisuales y plásticas que son perpetuadas por las mismas comunidades (Decreto n. 2.941, de 2009, art. 8).

La tradición oral en su condición como patrimonio -donde lo material e inmaterial, lo mítico, mágico y sobrenatural se mezclan con lo histórico, y lo material con lo inmaterial (Ocampo, 2011)- es dificil de asimilar de hecho a cualquier intento de catalogación.Así, en tanto la lógica oficial dominante para la gestión del patrimonio exige pensar lo material e inmaterial como elementos disociados, en la lógica de los actores sociales esos elementos conforman una unidad no separada, donde las fronteras que se suelen establecer entre ambas categorías de patrimonio son fluidas y no sólidas, como se acostumbran considerar (Romero, 2005).

El tercer reto obedece a la adecuada promoción, protección y conservación de la tradición oral. La naturaleza misma de la tradición oral parece incompatible con las prácticas conservacionistas y museísticas, caracterizadas -la mayoría de las veces- por privilegiar, en la protección del patrimonio, criterios a partir de los cuales se persigue su encapsulamiento en el pasado (Araujo, 2008). Lo cual suele ser más adecuadas a objetos muebles e inmuebles que a actividades, procesos o manifestaciones vivas de la cultura (Carrera, 2017).

La situación descrita se hace evidente en Colombia, donde las formas más comunes de intervención en esos patrimonios es proceder a fijarlas, pasándola del registro oral al registro escrito o grabaciones sonoras, en el intento de favorecer su preservación. Algo que obliga a ajustarles a "los cánones de la cultura escrita" (Álvarez, 2012, p. 24) y desconoce su condición dinámica y el peso que tiene ese cambio de registro, o el hecho de que, por lo general, ello supone someterles a otras estructuras narrativas y formas ajenas de organizar el discurso. Al tiempo, pasar de registro oral al material obliga, casi siempre, a dejar fuera elementos como las expresiones faciales, el movimiento del cuerpo, etc., empleados por los narradores para acompañar la recreación de sus relatos tradicionales. La escritura y grabación sonora de esos relatos representa, así, modalidades insuficientes de preservar la tradición oral, apartándola de su contexto de enunciación y resguardándola de cambios; por lo cual imponerles esas modalidades de gestión del patrimonio no puede resultar favorable.

El cuarto reto obedece a las dinámicas mismas de la tradición oral, que permite al narrador ser el autor y portador al mismo tiempo, aspecto que deriva en que se sometan a transformaciones constantes los textos que circulan en las comunidades y que 
ni siquiera el mismo narrador "emitirá dos versiones idénticas" (Guillén, 2016, p. 30). Como resultado, no existe una versión original de esos textos, sino múltiples versiones en distintos formatos, algunos más formales y otros más informales (Álvarez, 2012, p. 22-23).

La preeminencia de la originalidad de la obra y conservación de sus cualidades originales, tan valorada en el "culto a los monumentos" (Quintero, 2005) y el fetichismo de la piedra, no es así asimilable a las particularidades de esas manifestaciones de PIC.

La tradición oral está compuesta por una complejidad de elementos, entre los cuales podemos identificar estratos fijos y variables. Desconocer esa realidad es despojarles de su misma vitalidad y desconocer su condición como obra colectiva en permanente recreación/actualización. Así como su naturaleza misma, la cual Antonio Gramsci describe como conformada por la superposición de

[...] estratos fosilizados, que reflejan condiciones de vida pasada y, por tanto, son -a menudo- conservadores y reaccionarios, y otros que son una serie de innovaciones, creadoras y progresivas, determinadas espontáneamente por formas y condiciones de vida en proceso de desarrollo. (Gramsci apud Díaz, 2003, p. 132-133).

La situación descrita comparte gran importancia para el caso de los mitos, cuentos de espantos y leyendas. El historiador Luis Rubén Pérez (2016) considera que las diferentes versiones y variantes de un mismo relato persiguen, en esos casos, el objetivo de aportar a la credibilidad del mismo, permitiendo articular a personajes ficticios con hechos reales y comunes y a la ficción narrativa con el acontecimiento histórico. Los resultados de la actual investigación sugieren que en ciertos casos se incluyen también variaciones en los relatos tradicionales para "ajustar" el mismo en relación a los valores y conductas del contexto y momento histórico, esto es, para actualización.

Algunos de estos relatos ofrecen, incluso, características que permiten identificarlos como narrativas testimoniales y como tales merecen ser documentados. La tradición oral no depende, para su conservación, sólo de los mecanismos por los cuales se perpetúa, sino también de aquello por los que se reinventa; de éstos depende para encontrar un sentido a lo propio (Díaz, 2003). Así lo ilustra el siguiente relato: en él la referencia a las realidades históricas, culturales y materiales del contexto se convierten en los protagonistas principales, logrando recrear en el municipio del Socorro (Santander) una leyenda que los folcloristas colombianos consideran ampliamente extendida en la tradición oral de la Región andina colombiana y los santanderes:

La historia de la mula de las dos patas es precisamente a raíz de esas casas de balcones con las escaleras de madera.

Que había una viuda muy importante acá y tenía un amante; y el amante (para poder llegar y no ser observado) se le ocurrió amarrarles trapos a las patas delanteras de la mula que él montaba.Y, claro, entonces regó el cuento de que ese era el Diablo y que no se le podía verle ni a la cara, porqué el que se asomara a chismosear que era el ruido del golpe de dos cascos, jue' puerca, que a ese se lo llevaba el Diablo al infierno. Entonces la gente no miraba ni por las ventanas. 
Entonces se sentía el golpe de las dos patas, y el tipo subía con la mula hasta el segundo piso para acostarse con la viuda.Y entonces parecía que fuera una persona subiendo: ta, ta, ta. El Diablo hijuemadre. Ta, ta, ta. Claro, la mula subía hasta el segundo piso y después la bajaba por la misma escalera.Y eche. Un día alguien no se aguantó y dijo: “AAh!... el Diablo es Don fulano”.

- ¿En qué calle queda esa vivienda?

- Parece ser que es la casa de Berbeo. Ahí se ve la escalera de madera como en ángulo. ${ }^{3}$

El quinto reto obedece al interés por relacionar cada expresión de nuestro patrimonio a una cultura en específico, según criterios que suponen que un bien patrimonio es único en su tipo, exclusivo y expresión de singularidad de las comunidades portadoras. Caso contrario, el estudio de nuestra tradición oral devela que, por lo general, esta no solo se compone de continuidades históricas, nacionales y regionales, pero también de procesos como transformación, hibridación y reciclaje cultural.

El sexto reto responde a la condición de fugacidad en la cual se funda la oralidad, al hecho de que sus manifestaciones parezcan ser más frágiles al paso del tiempo que otros patrimonios, lo cual se considera pudiera limitar las posibilidades de recuperación o restauración de las mismas a futuro. Es decir, muchas de nuestras expresiones culturales de carácter inmaterial, intangibles y vivas, difícilmente podrán sobrevivir sin procesos de sensibilización y fortalecimiento.

La Constitución política colombiana del 1991 supuso cambios importantes para los marcos que hasta el momento dieron forma a la normatividad cultural; gracias a la Constitución, la diversidad cultural se reconoce como una realidad estructural del país. Ese reconocimiento tendría consecuencias similares, en Colombia, a las que en el mundo tendrían documentos como la Convención de la Unesco, de 1972; esto es, el tránsito de un marco normativo donde las diferencias se perciben como una amenaza, se invisibilizan o eliminan, a uno nuevo, donde la diversidad se exalta como una característica potencializadora del desarrollo humano y social (Peréz, 2012).

Años más tarde, la Ley n. 397, de 1997, o Ley General de Cultura, retomaría esas orientaciones de la Constitución y establecería los lineamientos generales a partir de los cuales el Estado asumiría la tarea de promover la diversidad cultural (art. 1). Las normatividades posteriores se ocuparían de ampliar y corregir esa Ley. Aun así, existen criterios ampliamente aceptados y difundidos en la legislación que resultan dificiles conciliar con las particularidades de las expresiones del PIC en el país (Bolívar, 1999). Ese aspecto limita las posibilidades de democratización de los procesos de declaratoria, considerando que las políticas para la declaratoria de nuestro patrimonio intervienen siempre en sus múltiples significados en el intento de promocionar un conjunto determinado de bienes y descalificar otros (Prats, 2006).

Al respecto, pueden resultar favorables los cambios que se describen en el siguiente apartado.

3 Relato aportado por el historiador y abogado Álvaro Sarmiento, en entrevista el 17 de septiembre de 2016 en el Parque de Chiquinquirá-Socorro. 


\section{“Miré, aquí está, aquí fue", turismo, memoria y tradición oral en el municipio del Socorro}

El municipio del Socorro (ubicado a $121 \mathrm{~km}$ al sur de la capital del departamento de Santander) ilustra la importancia de superar la situación descrita en el apartado anterior y las posibilidades que la tradición oral ofrece para la puesta en valor de los patrimonios locales en el caso de Colombia. Tradicionalmente, el municipio se ha convertido en destino turismo de interés histórico y religioso, lo cual se explica debido a su importante participación en eventos claves para la historia nacional y por las evidencias arquitectónicas y monumentales que conserva de tiempos pasados. Al igual que por el hecho de servir como escenario de peregrinación para los devotos de laVirgen del Socorro y lugar donde se ubica la majestuosa Catedral del Socorro, recientemente reconocida con el título de Basílica menor.

A pesar de esos hechos, se lamenta la situación de riesgo originada por causa del descuido a su patrimonio arquitectónico y la desatención de su importancia para la historia nacional. Esos aspectos son fáciles de asociar con un improvisado proceso de integración del municipio al turismo en la Región.

Así se justifica la afirmación de los expertos entrevistados, muchos de los cuales consideran que "la gente viene al Socorro, a ver la Catedral y la Casa de cultura, a comer rico, tomarse unas foto y nada más". ${ }^{4}$ Faltan, así, estrategias para potenciar esos atractivos, pues al turista hay que decirle "Miré, aquí está, aquí fue". 5

La conjunción de intereses entre el turismo cultural y las políticas culturales ha convertido el patrimonio cultural en tema de interés de públicos diversificados para el caso de algunos contextos latinoamericanos; así, instituciones públicas y privadas, profesionales y empresas, portadores de estas tradiciones culturales y públicos en general se interesan hoy por el patrimonio como un recurso comercializable de cara al turismo y no sólo como un objeto del pasado que, por derecho, debe ser conservado (Moragas, 2007). Coyuntura que puede resultar favorable para el caso de nuestra tradición oral, considerando que su apuesta en valor involucrar también a múltiples actores sociales (Fontal, 2003).

Entre las circunstancias que acompañan este maridaje de turismo y patrimonio resulta de interés para el artículo los cambios que ocasiona en los procesos de "patrimonialización" (Prats, 2003).

Actualmente, es evidente el aumento cuantitativo en los territorios, objetos y prácticas consideradas como patrimonio. Sin embargo, a ese aumento cuantitativo del patrimonio no siempre se ha sumado un cambio cualitativo en las nociones que se comparten respecto a qué caracteriza al patrimonio cultural. Así, aunque la normatividad

4 José de Carmen Rangel, historiador local, en entrevista con Giovanni Bohórquez Pereira el 16 de junio de 2016.

5 Ibíd. 
incentiva a postular "nuevos patrimonios", son necesarios cambios que abran la posibilidad a nuevas concepciones del patrimonio. El primer cambio es el paso de una definición de patrimonio tradicionalmente orientada por la definición técnica fundada en lo artístico e histórico (Lacarrieu, 2009), a una fundada en la cuestión de representatividad, reivindicación y autorreferencia de los colectivos (Quintero, 2005). Aspecto frente al cual se han presentado avances en el caso del patrimonio inmaterial y las políticas culturales que se formulan al respecto, con todo, aún falta camino por recorrer.

La Convención para la salvaguardia del patrimonio cultural inmaterial del 17 de octubre de 2003 identifica el turismo y el mercado "como factores que pueden contribuir al fortalecimiento y/o revitalización de una manifestación cultural intangible" (Marcos, 2009, p. 180). Algo de gran importancia dado a que, además, se invita, en esa Convención, a privilegiar las modalidades de gestión del PIC que centran su atención en la apropiación social del mismo, y a conseguirlo involucrando a sus portadores, a los habitantes de la localidad y a sus diversos beneficiarios, como gestores y vigías de esas propuestas. Antes de seguir con la presentación de los riesgos que pueden enfrentar los PIC de cara a su promoción como recurso para el turismo, no sobra recordar también los desafortunados resultados que se consiguen cuando son los decretos y declaratorias las únicas medidas orientadas a conseguir la preservación del patrimonio.

El turismo y el patrimonio cultural conforman una relación compleja, en algunos casos exitosos, en otros no.Además de ser un incentivo para que las comunidades revitalicen sus tradiciones, suele ocasionar un énfasis inadecuado en la continuidad de la tradición y alentar el intento por ocultar el carácter contingente de las expresiones culturales que se ponen al servicio de la mirada del turista (Lagunas, 2010).

Los patrimonios ofertados al turismo suelen ser legitimados por discursos asociados a la monumentalidad (Lacarrieu, 2010) y a la "excelencia cultural" (Lacarrieu, 2009), olvidándose de la importancia que tiene el "discurso de lo cotidiano" (Santos Goncalves apud Mónica Lacarrieu) en la legitimación de los mismo. Así, para caracterizar como atractivos turísticos lugares como la Torre Eiffel, la Estatua de la Libertad, la Torre de Pisa o la Muralla China, entre otros, se emplean procesos donde se rompe la relación entre los patrimonios y los contextos de la vida cotidiana, para luego integrarles a la historia y progresos de la humanidad.

La asociación entre turismo y gestión del patrimonio cultural representa también riesgos como la mercantilización del patrimonio. Es decir, el riesgo de sustituir a la conciencia patrimonial por una conciencia comercial está presente siempre que se impone el interés por obtener beneficios económicos (López, 2007, p. 67). Al respecto, si en el caso del Patrimonio Material Cultural los riesgos redundan en su posible destrucción como resultado de la intervención y promoción como recurso turístico, para el PIC los riesgos a ello asociados son el posible sacrificio de su capacidad de renovación y condición como testimonio de un colectivo social (resultado del interés de potenciar su atractivo como espectáculo).La tradición oral sufre, como resultado, procesos de fosilización, anacronismo, 
y se afecta gravemente su capacidad para sobrevivir entre generaciones y las condiciones exigidas para su divulgación.

La formación, capacitación, divulgación y sensibilización es, en ese punto, esencial; esto es, se requiere fomentar el protagonismo de los portadores tradicionales para que sean ellos los principales convocados en la identificación, salvaguarda y puesta en valor del patrimonio (García, 2014). Algo que, en esencia, implica generar apuestas educomunicativas, donde los portadores de esas tradiciones sean sus legítimos intérpretes y custodios (Cánepa, 2009); vincular a la población local y lograr que ellos mismo se enamoren de lo que son.

La puesta en valor y participación de los portadores de la tradición oral se convierte, de esa forma, en un componente esencial para su salvaguardia. Citando a la Unesco en 2003 (art. 2):

[...] prácticas, representaciones y expresiones, los conocimientos y las técnicas que dan a las comunidades, los grupos e individuos un sentimiento de identidad y continuidad. Los instrumentos, herramientas, objetos, artefactos y espacios culturales asociados a esas prácticas forman parte integrante de este patrimonio. El PIC, transmitido de generación en generación, de pueblo en pueblo, lo recrean permanentemente las comunidades y los grupos en función de su medio, su interacción con la naturaleza y su historia. (MinCultura, 2011, p. 17).

El turismo sobrenatural ofrece, en esos casos, una alternativa a menudo exitosa. La aceptación de los públicos por esas modalidades de turismo es un aspecto aún por establecer y a ello deberán estar orientadas futuras investigaciones. Diversos antecedentes muestran, sin embargo, que se puede convertir en una estrategia ventajosa como atractivo para invitar al turista a visitar escenarios históricos y de potencial patrimonial (Valdez, 2010), siempre y cuando se cuente previamente con un diagnóstico o relación de los elementos del patrimonio que pueden representar atractivos turísticos culturales (De la Puente; Martínez; Spitale, 2012).

Aunque varios de esos aspectos sobrepasan los intereses del actual trabajo, es posible afirmar que la formulación de recorridos turísticos con elementos de nuestra tradición oral puede servir también como materia prima para diversificar la oferta de turismo cultural en la Región de los santanderes, y a ello se suma su condición como alternativa de turísticos sostenibles en el área de estudio, particularmente debido a sus potencialidades como material para construir itinerarios turísticos y al hecho de vincular a los portadores de esas tradiciones en su divulgación. Además, es evidente la asociación que la tradición oral establece entre el patrimonio monumental y arquitectónico y otras manifestaciones del patrimonio; lo cual sirve para superar una debilidad común en las disposiciones que tradicionalmente se emplean para la protección y preservación del patrimonio cultural.

El siguiente relato, correspondiente a una de las leyendas más queridas del Socorro, "La sirena de la Catedral", deja en claro los motivos de esa última afirmación. El relato 
corresponde a Carlos Alberto Bautista, carpintero, pintor y tapicero, nacido en el Socorro el 28 de mayo 1948 y entrevistado el 05 de abril de 2010:

Decían los abuelitos, de aquí del pueblo, que en la iglesia de la Catedral, allí habían 14 aljibes. Habían 2 en lo que es hoy el altar mayor, habían 2 en la casa cural y por la parte de arriba todo eso era solo de aljibes. Y está el de abajo.

El de abajo dicen que es un brazo del mar.Y que en tiempos se oían una voz muy melodiosa de una mujer que cantaba. Y entonces decían que eso era una Sirena que se oía ahí cantar.

$[\ldots]$

Y eso decían que la iglesia estaba parada porque el aljibe lo atravesaba una barra de oro que lo había ahí atravesado, y que el día que se parta, la iglesia se cae.Y de raro, no puede haber nada de raro, porque en estos momentos la iglesia está partida por mitad.

$[\ldots]$

Baje usted por toda la calle 14, llega a donde es Vanguardia liberal hoy, mire la pared, mire hacia arriba y verá que ya la iglesia se partió. Está partida.Ya en la pared hay unos ventanales que están vencidos hasta unos veinte centímetros, todos se está abriendo.

Y esa partidura da vuelta redonda.Y pasa por el aljibe.

Iglesias, colegios, calles, lugares de importancia histórica y turística, etc., sirven como escenarios para mitos, leyendas y cuentos de espanto en el Socorro.Así, no resulta exagerado afirmar que en el municipio la tradición oral es el lugar donde el pasado se integra al presente y el territorio se asocia al patrimonio para escenificar la cultura, condición necesaria para su reconocimiento como "escenarios de la memoria" (Nora, 2008). Aspecto clave también para rehabilitar el patrimonio cultural local, su representatividad y, al tiempo, favorecer el fortalecimiento de aspectos como su relevancia y vigencia.

El patrimonio inmaterial y material de la localidad se encuentran así fuertemente entreverados; en el municipio las leyendas recorren numerosos caminos, históricos, geográficos, culturales y sobrenaturales, entre otros. Eso invita a cuestionar la dicotomía material-inmaterial presente en los procesos tradicionales de gestión de patrimonio cultural (Bouchenaki, 2003).

La asociación de esas expresiones de tradición oral con escenarios reales e imaginarios del municipio del Socorro ocurre, según se refiere al inicio de este escrito, "en una mezcla en la cual se entronca lo fantástico con lo histórico" (Ocampo, 1996, p. 36). Algo que sugiere también su importancia como recurso útil para abordar diversos temas, al tiempo que determina un aspecto crucial para su elección como material de interés en el marco del turismo cultural. De eso se derivan circunstancias como que elementos estudiados por disciplinas diversas e incluso, pertenecientes a diferentes categorías del patrimonio según la normatividad cultural, pueden formar parte de esos recorridos. Al igual que el reconocimiento de la tradición oral como alternativa a sumar junto a los demás atractivos turísticos del municipio, debido a que conserva un adecuado equilibrio entre satisfacer 
la demanda externa y las de quienes hasta el momento han sido sus custodios y a que gracias a narrativas diversas permite conectar las diferentes manifestaciones de patrimonio cultural de la localidad.

Los beneficios y posibles impactos del turismo sobrenatural a la región se puntualizan en la siguiente figura. Los más importantes obedecen a sus potencialidades económicas, sociales y educativas.

Figura 1 - Relaciones entre la tradición oral y turismo cultural

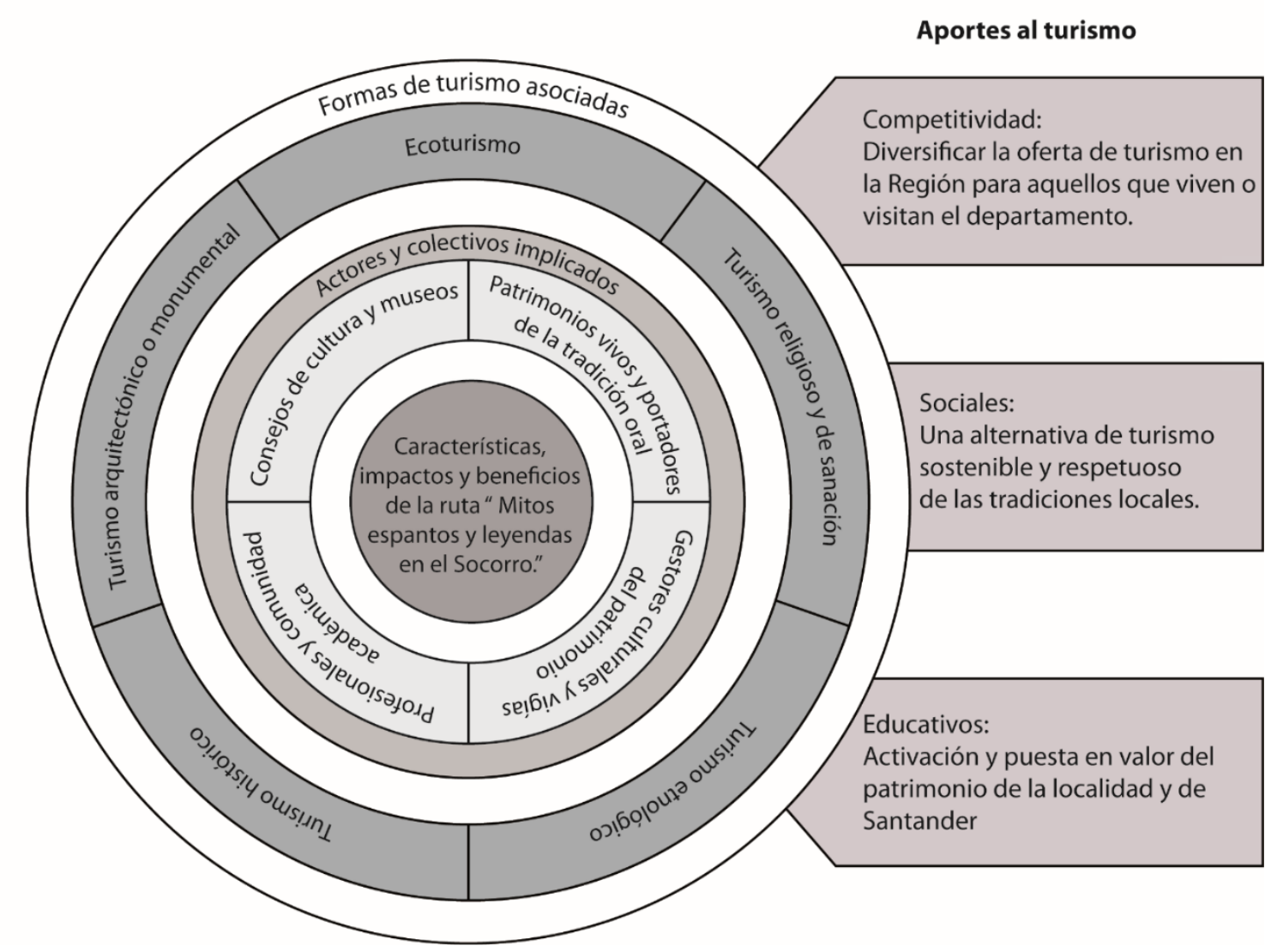

\section{Conclusiones}

La tradición oral se ha consolidado recientemente como atractivo para el turismo y esto mueve a reconocer su importancia como expresión de la identidad nacional y local, al tiempo que también ha ocasionado la integración de diversas manifestaciones de PIC a la categoría de patrimonio de la Humanidad.

Los resultados de este trabajo sugieren la importancia de revisar las fronteras fijas que la normatividad suele emplear de cara la clasificación, inventario y estudio del patrimonio cultural, particularmente las fronteras entre lo material e inmaterial, el objeto y su contexto, la gestión técnica especializada y la participación ciudadana, al igual que las diferentes manifestaciones de nuestro patrimonio cultural, al tiempo que conduce a revisar los criterios que la normatividad emplea para orientar la puesta en valor de esos patrimonios. 
La normatividad cultural en Colombia ha avanzado en aspectos como son la integración de diversas formas de tradición oral al catálogo de patrimonios culturales y la formulación de instrumentos como los Planes de Especiales de Manejo y Protección (PEMP); sin embargo, la integración de esas expresiones culturales al catálogo de bienes elegibles como patrimonio no es suficiente, es necesario, además, sumar a ese reconocimiento medidas para la promoción, financiación y sostenibilidad de nuestro patrimonio "vivos". Lo mencionado en este trabajo involucra, aunque no se limita, a la tradición oral.

El turismo sobrenatural es una alternativa a considerar debido a sus aportes en aspectos como el fortalecimiento de la capacidad de gestión cultural entre los portadores de esos patrimonios y también a que, gracias a su condición como escenario de encuentro entre las diversas manifestaciones de patrimonio cultural, sirve para reducir la brecha impuesta entre el patrimonio material e inmaterial.

\section{Referencias}

ÁLVAREZ, Gabriela. Los relatos de tradición oral y la problemática de su descontextualización y re-significación, 2012. Tesis (Maestría en Escritura y Alfabetización) - Universidad Nacional de La Plata, Buenos Aires, Argentina, 2012.

ARAUJO, Alejandro. De los imaginarios a las prácticas. La conservación de los centros históricos: tensión y complejidad social. Revista de Historia Internacional, n. 35, p. 91-109, 2008.

BARELA, Liliana; MIGUEZ, Mercedes; CONDE, Luis García (eds.). Algunos apuntes sobre historia oral. 4. ed. Buenos Aires: ed. Instituto histórico de la ciudad de Buenos Aires, 2004.

BOLÍVAR, Edgar. Patrimonio cultural: algo más que objetos, algo más que pasado. Revista territorio, n. 2, p. 3-18, 1999.

BOUCHENAKI, Mounir. "The interdependency of the tangible and intangible cultural heritage". En: 14th ICOMOS General Assembly and International Symposium: 'Place, memory, meaning: preserving intangible values in monuments and sites', p. 27-31, 2003.

CARRERA, Gema. Patrimonio inmaterial: reduccionismos, conflictos e instrumentalizaciones. Revista Andaluza de Antropología, n. 12, p. 1-30, 2017.

CÁNEPA, Gisela. La gestión de la cultura inmaterial: del archivo al repertorio. En: ENCUENTRO PARA LA PROMOCIÓN Y DIFUSIÓN DEL PATRIMONIO INMATERIAL DE PAÍSES IBEROAMERICANOS, 10., 2009, Lima. Fiestas y Rituales: X Encuentro para la promoción y difusión del patrimonio inmaterial de países iberoamericanos. Lima: Corporación para la Promoción y Difusión de la Cultura, 2009. p. 96-110.

CORTÁZAR, Francisco. ¿Qué hay de nuevo?: rumores y leyendas urbanas en Internet. Colección de Babel-separata de la Revista de la Universidad de Guadalajara, v. 32, p. 48-60, 2004.

DE LA PUENTE, Ana; MARTÍNEZ, Griselda; SPITALE, Paola. Diagnóstico de la potencialidad turística del patrimonio cultural inmaterial. Estudio de casos: dptos. Arauco y San Blas de los Sauces, La Rioja - Argentina. TUR $y$ DES, v. 5 n. 13, p. 1-12, 2012.

DÍAZ, Luis. El regreso de los lobos: la respuesta de las culturas populares a la era de la globalización. Madrid: Departamento de Antropología de España y América/Consejo Superior de Investigaciones Científicas, 2003.

FARRÉ, Marta. Coleccionistas de los olvidos. La(s) memoria(s) como estrategia local de supervivencia. En: ANDREU, Agustín et al. Periferias, fronteras y diálogos: una lectura antropológica de los retos de la sociedad actual. Tarragona: Universitat Rovira i Virgili (Ed.), 2014. 
FERNÁNDEZ, Esther. De tesoro ilustrado a recurso turístico: el cambiante significado del patrimonio cultural. Pasos: Revista de turismo y patrimonio cultural, v. 4, n. 2, p. 1-13, 2006.

FERRANDO, Emili. Fuentes orales e investigación histórica: orientaciones metodológicas para crear fuentes orales de calidad en el contexto de un proyecto de investigación histórica. Barcelona: Ediciones del Serbal, 2006.

FONTAL, Olaia. La educación patrimonial. Teoría y práctica en el aula, el museo e internet. Astúrias: Ediciones TREA, 2003.

GALINDO, Mauricio; GARCÍA, Carlos;VALENCIA, Jorge (AA.VV). Mitos y leyendas de Colombia: tradición oral indígena y campesina. Bogotá: Intermedio editores, 2003.

GARCÍA, Guillermo. Patrimonio, apuntes de gestión. Buenos Aires: Ed. Diseño-Grupo Habita, 2014.

GUANCHE, Jesús. El imaginado "patrimonio inmaterial” ¿Un acercamiento a la verdad o una falsedad engañosa? Revista Arte E diseño, v. 12, n. 1, p. 62-71, 2014.

GUILLÉN, Adriana. Personajes y espacios sobrenaturales en la tradición oral de Coatepec, Veracruz. 2016. Tesis (Maestría en literatura Hispanoamericana) - Colegio de San Luis de México, 2016.

GUBER, Rossana. El salvaje metropolitano. Reconstrucción del conocimiento social en el trabajo de campo. Buenos Aires: Ed. Paidós, 2003.

HENRÍQUEZ, María. Lo que el ojo no ve. Políticas de lo inmaterial. Revista Atlántida: Revista Canaria de Ciencias Sociales, n. 3, p. 193-208, 2011.

HERRERA, Fermín. Los usos del folclore en California. En:VALENZUELA, José M. (Coords.). Entre la magia y la historia: tradiciones, mitos y leyendas de la frontera. México: ed. Plaza y Valdez, 2000.

LACARRIEU, Mónica. De "turistas" y "viajeros" en el mundo trasnacional: retos, desafíos y problemas del turismo cultural-patrimonial. Études caribéennes, p. 1-34, Décembre 2009.

LACARRIEU, Mónica. Procesos de patrimonialización material-inmaterial de los cementerios: valoración, transmisión y gestión. En: ENCUENTRO IBEROAMERICANO DE VALORACIÓN Y GESTIÓN DE CEMENTERIOS PATRIMONIALES, XI., 2010, Paysandú. Paysandú: ed. Ministerio de Educación y Cultura de Uruguay, 2010. p. 55-74.

LAGUNAS, David. Antropología, cultura y turismo (y un ejemplo). En: FOURNIER, Patricia; LÓPEZ, Fernando. Patrimonio, identidad y complejidad social: enfoques interdisciplinarios. México, DF: Escuela Nacional de Antropología e Historia, 2010.

LÓPEZ, Loreto. Catástrofes y fatalidades, o el patrimonio imposible. Serie Documentos, n. 2, p. 1-16, 2007.

MADEROS, Fernando. La riqueza etnográfica. En: I. ALBA, José Ramón;VAL MORENO, Elena (Coords.). Turismo y gestión del territorio. Zaragoza: ed. Diputación Provincial de Zaragoza, 2005.

MARCOS, Javier. El patrimonio como representación colectiva. La intangibilidad de los bienes culturales. En: MEDINA, Eusebio et al. (Coord.). Fronteras, patrimonio y etnicidad en Iberoamérica. España: Signatura Demos, 2009.

MINISTERIO DE CULTURA. Patrimonio cultural inmaterial en Colombia. Bogotá: Editorial Nomos S. A., 2011.

MINISTRO DEL INTERIOR Y DE JUSTICIA. Decreto n. 2.941, de 2009. Disponible en: http://www. alcaldiabogota.gov.co/sisjur/normas/Norma1.jsp?i=37082. Acceso en: 2 de diciembre de 2018.

MORAGAS, Natalia. Patrimonio histórico, turismo y desarrollo local: un reto del siglo XXI. En: LAGUNAS, David (Coord.). Antropología y turismo: claves culturales y disciplinares. México: Plaza y Valdez ed., 2007.

NORA, Pierre. La aventura de "Les lieux de mémoire". Montevideo: Ediciones Trilce, 2008.

OCAMPO, Javier. Leyendas populares colombianas. Bogotá: Plaza y Valdez ed., 1996.

OCAMPO, Javier. Manual del folclor colombiano. Bogotá: Plaza y Valdez ed., 2011.

PASTOR, María José. El patrimonio cultural como opción turística. Horizontes Antropológicos, v. 9, n. 20, p. 97-115, 2003. 
PÉREZ, Alexander. De la diferencia como amenaza a la diversidad como potencia: reflexiones en torno a la relación entre ciudadanía intercultural e intervención en lo social. Eleuthera, n. 7, p. 264-281, 2012.

PÉREZ, Luís. Literatura folclórica Leyendas y relatos legendarios de Piedecuesta. 2016. Informe de investigación (Proyecto Leyendas y seres legendarios del sector rural de Piedecuesta) - Universidad Autónoma de Bucaramanga, 2016.

PRATS, Llorenç. La mercantilización del patrimonio: entre la economía turística y las representaciones identitarias. PH Boletín del Instituto Andaluz del Patrimonio Histórico, n. 58, p. 72-80, 2006.


127-136, 2003.

QUINTERO,Victoria. El patrimonio intangible como instrumento para la diversidad cultural ¿una alternativa posible? En: CARRERA, Gema; DIETZ, Gunther (Eds.). Patrimonio inmaterial y gestión de la diversidad. Sevilla: Consejería de Cultura, 2005.

ROCHE, Michelle. Nuestro desafio es pasar de la diversidad cultural a la interculturalidad. El Nacional, 11 de marzo de 2013. Disponible en: http://masantropologia.blogspot.com.co/2013/03/nuestro-desafio-es-pasar-dela.html. Acceso en: 20 de septiembre de 2012.

ROMERO, Raúl. ¿Cultura y desarrollo? ¿Desarrollo y cultura? Propuestas para un debate abierto. Cuadernos PNUD, serie 9. Lima: ed. UNESCO, 2005.

RENGIFO, Antonio. Avances y perspectivas del derecho para la restitución de bienes culturales a sus países de origen: el caso del patrimonio cultural Quimbaya. Pensamiento Jurídico. Antropología, derecho y política, v. 11, n. 22, p. 17-48, 2008.

SUÁREZ, Niria. La investigación documental paso a paso. Mérida: ed. Universidad de los Andes de Venezuela, 2011.

UNESCO. Convención para la salvaguardia del Patrimonio Inmaterial. Paris: ed. Unesco, 2003.

UNESCO. ¿Qué es el patrimonio cultural inmaterial? Section of Intangible Cultural Heritage. Disponible en: https:// ich.unesco.org/doc/src/01851-ES.pdf.Consultado el 14 de enero de 2018

VALDEZ, Raúl. Leyendas de fantasmas del centro histórico de Puebla, México. ¿Un recurso complementario de atracción turística? Revista Estudios y perspectivas en turismo, v. 19, n. 4, p. 553-569, 2010.

\title{
Myths, scary stories and legends: oral tradition in Socorro, Colombia
}

\begin{abstract}
The activation of heritage is the starting point of many goals. One of them is the safeguarding which begins with the inventory and cataloging of the cultural heritage of a country, region or community. This procedure faces particular challenges when it comes to manifestations of the oral tradition such as those in Colombia called "cuentos de espantos" - scary stories, frightening stories related to supernatural characters and spaces transmitted by the oral tradition. Most of the challenges have to do with their financing, sustainability, lack of regulation adjusted to the needs of our particular oral tradition and or background research on the subject. Discussing the challenges and presenting the possibilities to overcome them, articulating oral tradition with cultural tourism is the aim of this paper.
\end{abstract}

Keywords: Oral tradition. Scary stories. Supernatural heritage. Cultural tourism. Heritage appreciation. 


\section{Mitos, histórias de assombração e lendas: tradição oral no município de Socorro, Colômbia}

\section{Resumo}

A ativação do patrimônio é o ponto de partida para vários objetivos. Um deles é a salvaguarda, que começa com o inventário e a catalogação do patrimônio cultural de um país, região ou comunidade. Esse procedimento enfrenta desafios particulares quando se trata de manifestações da tradição oral como as que na Colômbia recebem o nome de "cuentos de espantos - histórias de assombração", histórias lúgubres e assustadoras relacionadas com personagens e espaços sobrenaturais, transmitidos pela tradição oral. A maioria dos desafios têm a ver com o seu financiamento, sustentabilidade, ausência de regulamentação ajustada às necessidades de nossa tradição oral ou de antecedentes em pesquisa sobre o tema. Discutir os desafios e apresentar as possibilidades de superá-los, articulando a tradição oral com o turismo cultural, é o objetivo desse documento.

Palavras-chaves: Tradição oral. Histórias de assombração. Patrimônio sobrenatural. Turismo cultural. Valorização do patrimônio. 